\title{
Monitoring Antibiotic Resistant Bacteria in the Black Hawk Lake Watershed, Iowa
}

Timothy P. Neher, Michelle L. Soupir

Agricultural and Biosystems Engineering



Contact:

Tim Neher tpneher@iastate.edu 


\section{Overview}

- Study Background

- Study objective

- Methods

- Results from first year of monitoring

- Initial conclusions

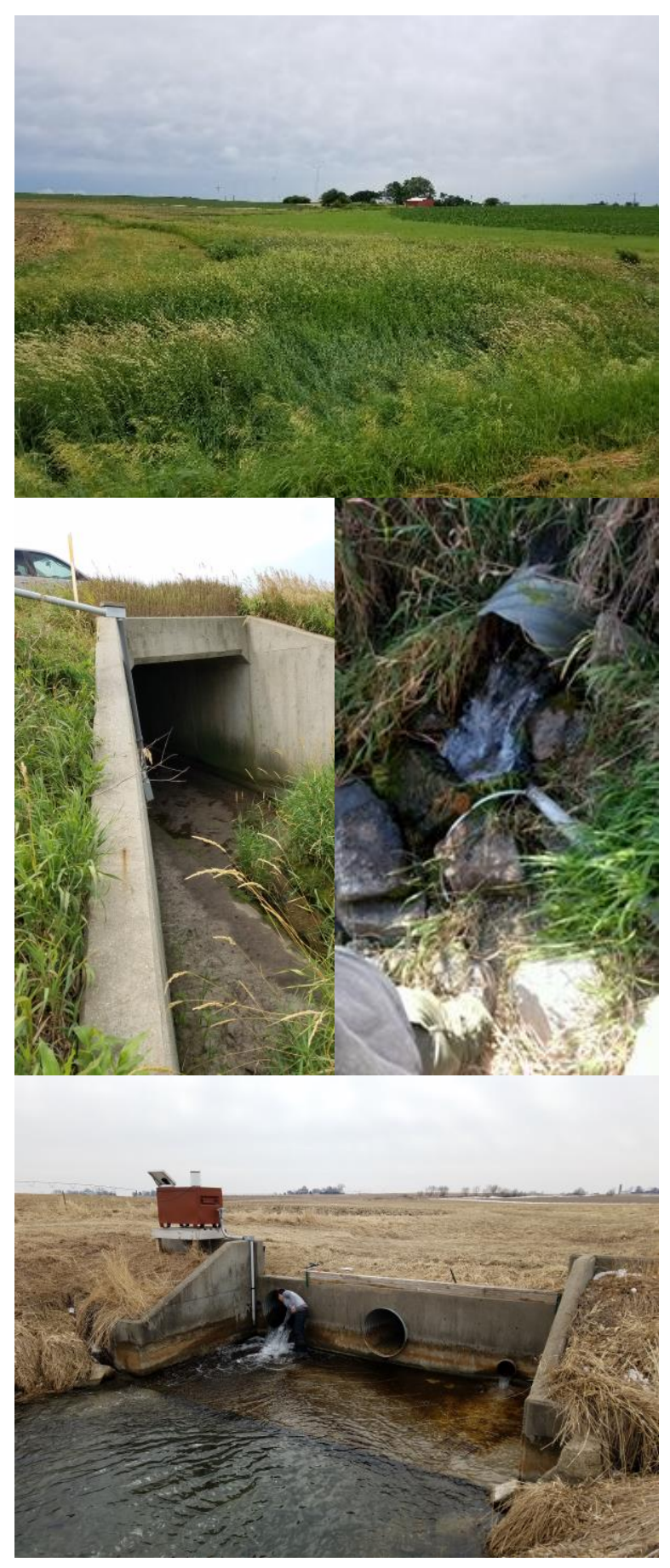




\section{Antibiotic use in Agriculture}

Estimated Annual Totals from 2016 (medically important)

Cattle: 7,960,766 lbs

Swine: 6,907,660 lbs

Veterinary Feed Directive 2017 - Makes medically important antibiotics illegal to use for production purposes and requires veterinary approval for prevention and treatment.

This study focuses on:

-Tylosin (Macrolide): Cattle and swine

-Ex. Erythromycin is a macrolide used when a patient is allergic to penicillin

-Tetracyclines: Human, swine, and poultry

-Ex. Used in acne products and to treat a number of infections 


\section{Sources of Fecal Indicator Bacteria in the environment}

- Wildlife - mostly geese

- Septic Systems - leakage, residual

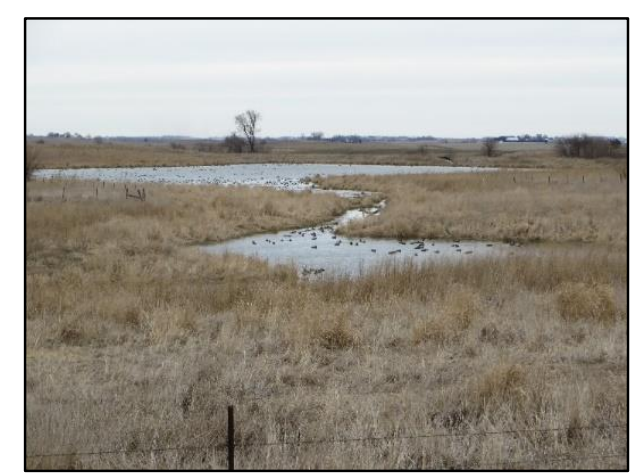

- Manure application on row crops as fertilizer

- Concentrated Animal Feeding Operations (CAFOs)
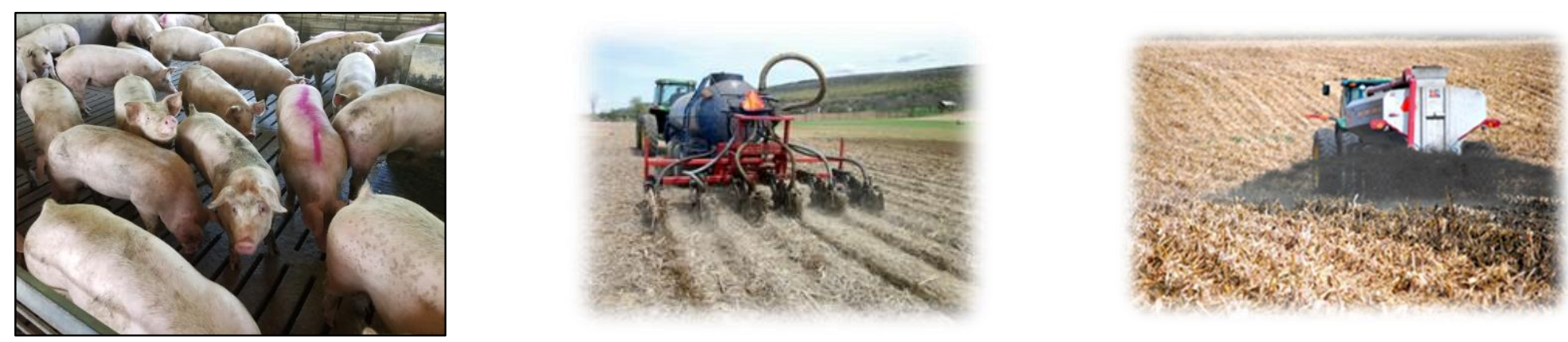


\section{NWQI Monitoring Project}

- 5-year project (2015-2019) sponsored by lowa DNR to analyze water quality in three subwatersheds within Black Hawk Lake watershed.

- Compliments existing DNR watershed and lake monitoring.

- Opportunity to monitor bacteria

- Lead to USDA funding for bacteria monitoring

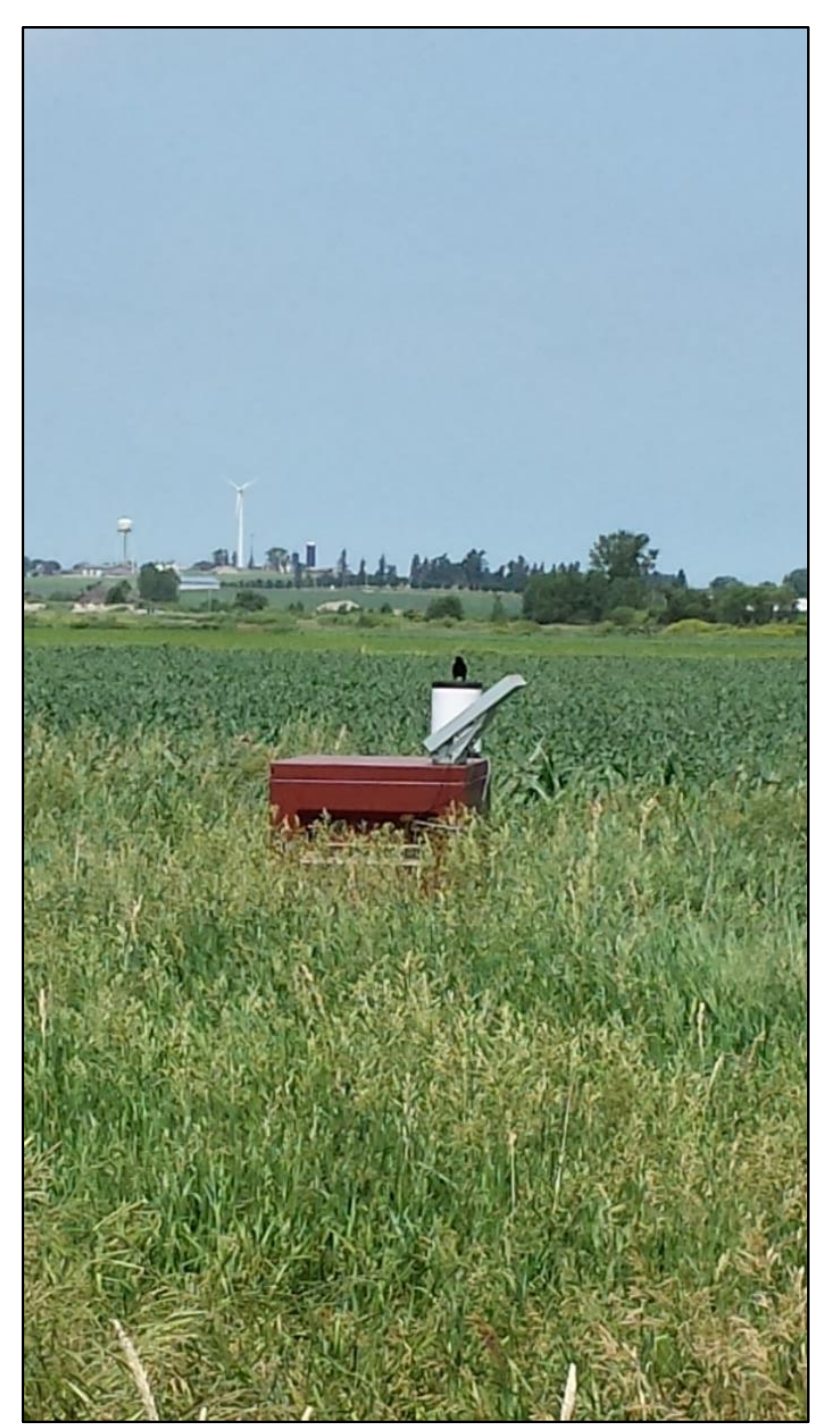




\section{Black Hawk Lake}

Watershed

- Located in the western portion of the Des Moines Lobe

- Located in both Sac and Carroll Counties

- Watershed Area: 13,156 acres

\section{Land uses:}

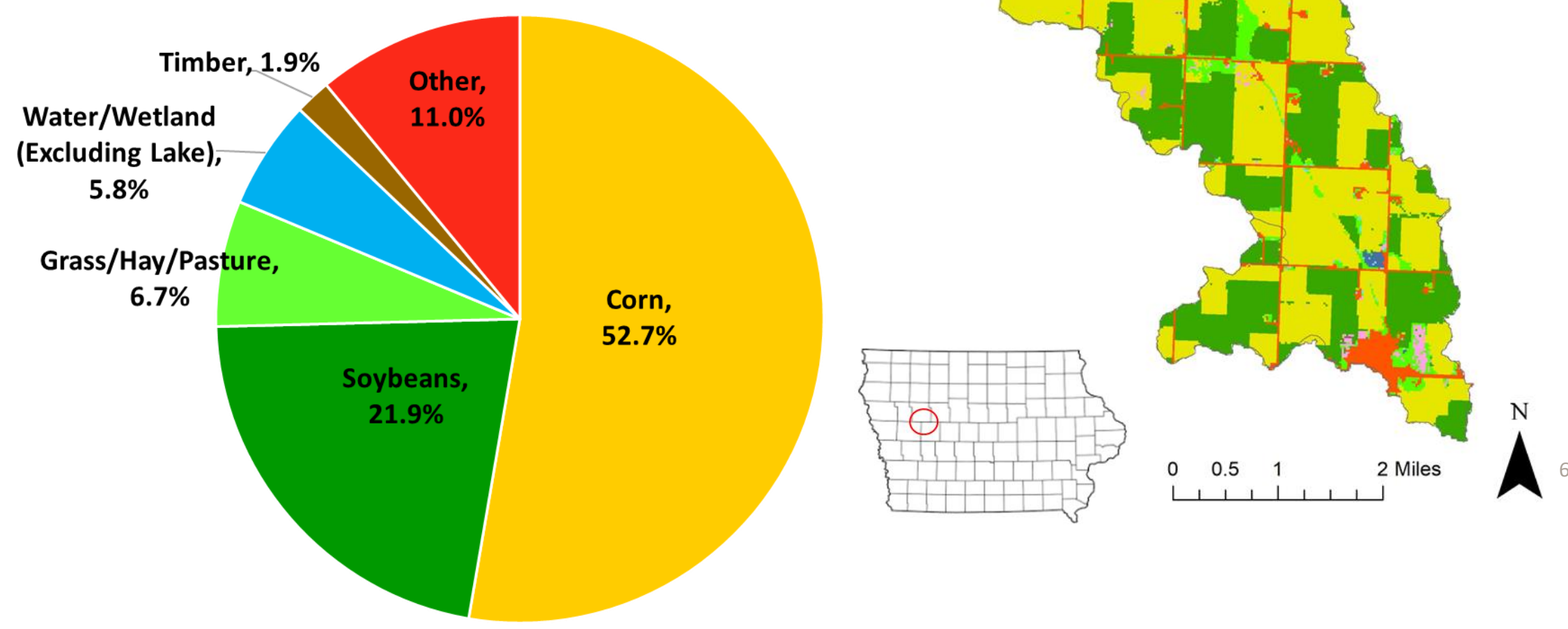




\section{Black Hawk Lake Watershed}

\section{Concern:}

- Enrichment of the natural environment with antibiotic resistant bacteria

- Harmless antibiotic resistant bacteria can pass resistance genes to pathogenic (infection causing) bacteria

\section{Broader Impact:}

- May eventually make its way to public areas

- Cause drug-resistant

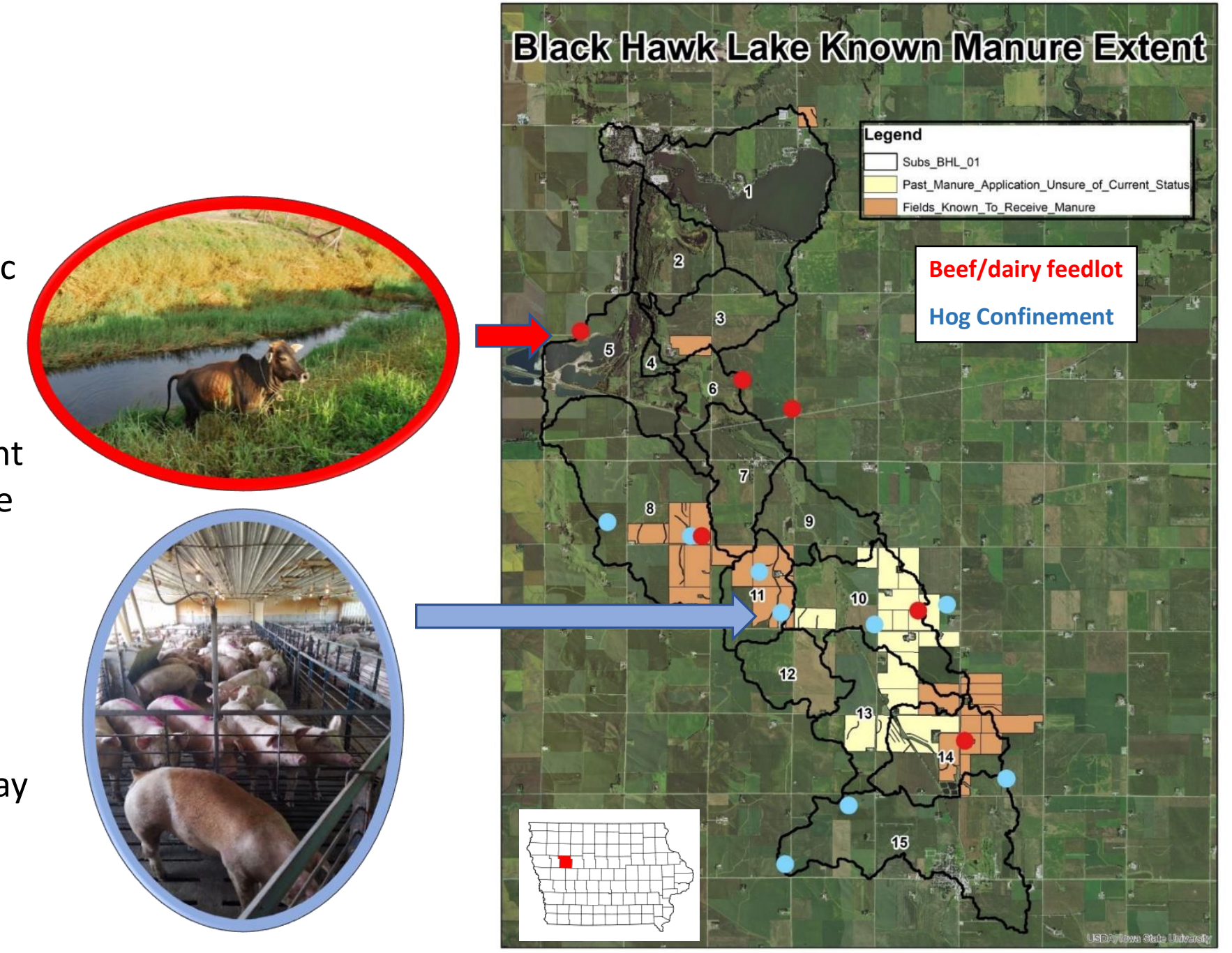

Black Hawk Lake Kinown Manure Extent infections 


\section{Study Objective}

- Monitor total fecal indicator bacteria (FIB) (E.coli and enterococci) and tylosin and tetracycline resistant enterococci from drainage and runoff in a highly agriculturalized watershed

Two year sampling effort, Summer 2017- Late Fall 2018
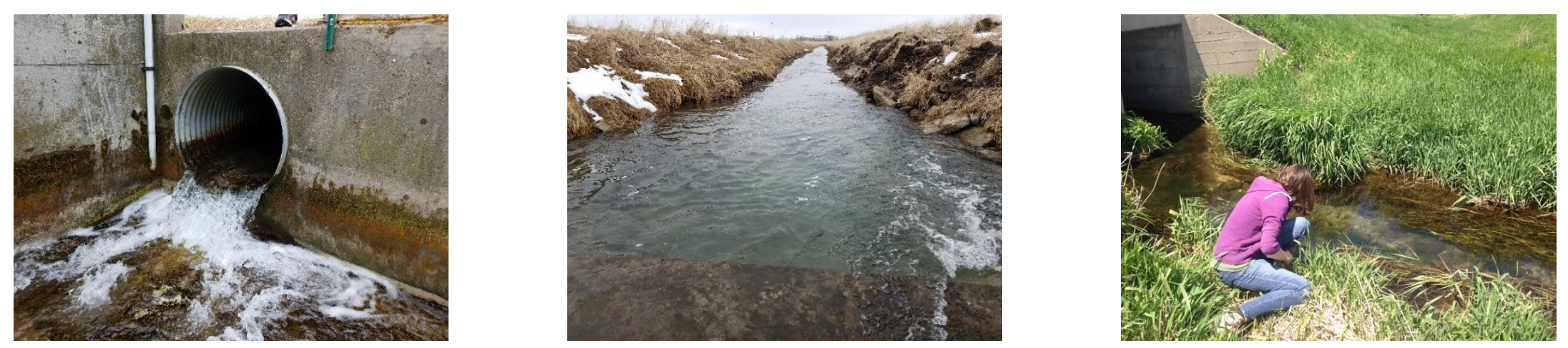


\section{BHL watershed has differences in manure application, tile and surface drainage, and best management practices}

\section{Manure Application}

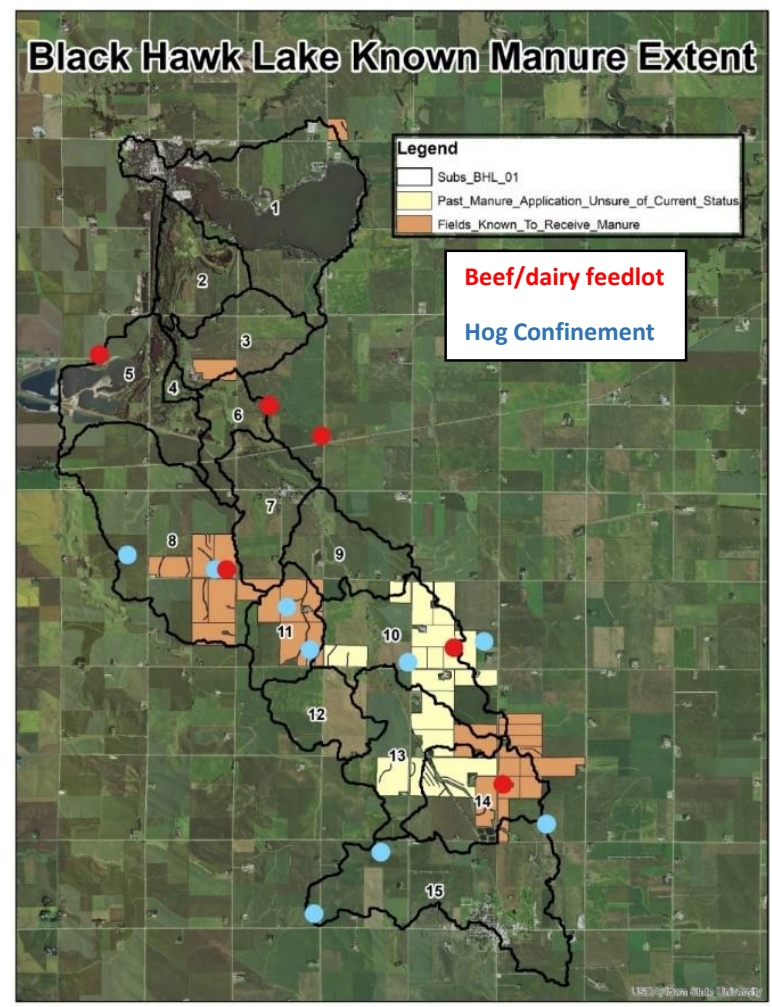

Tile and Surface drainage

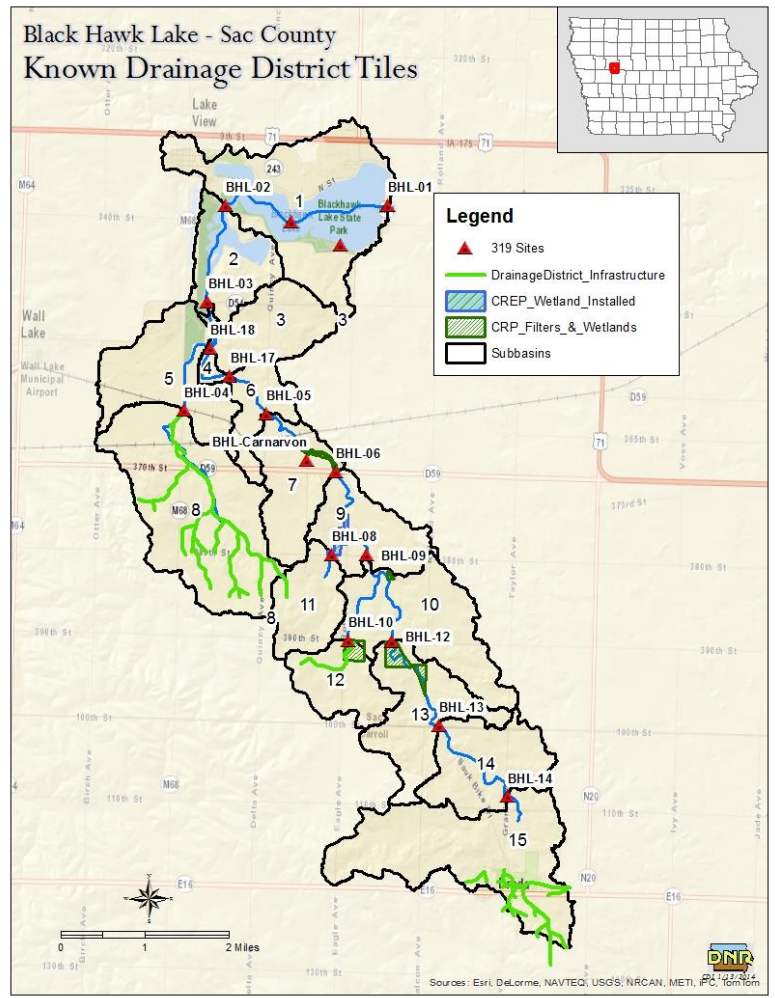

Best Management Practices

Black Hawk Lake Watershed Conservation Practices

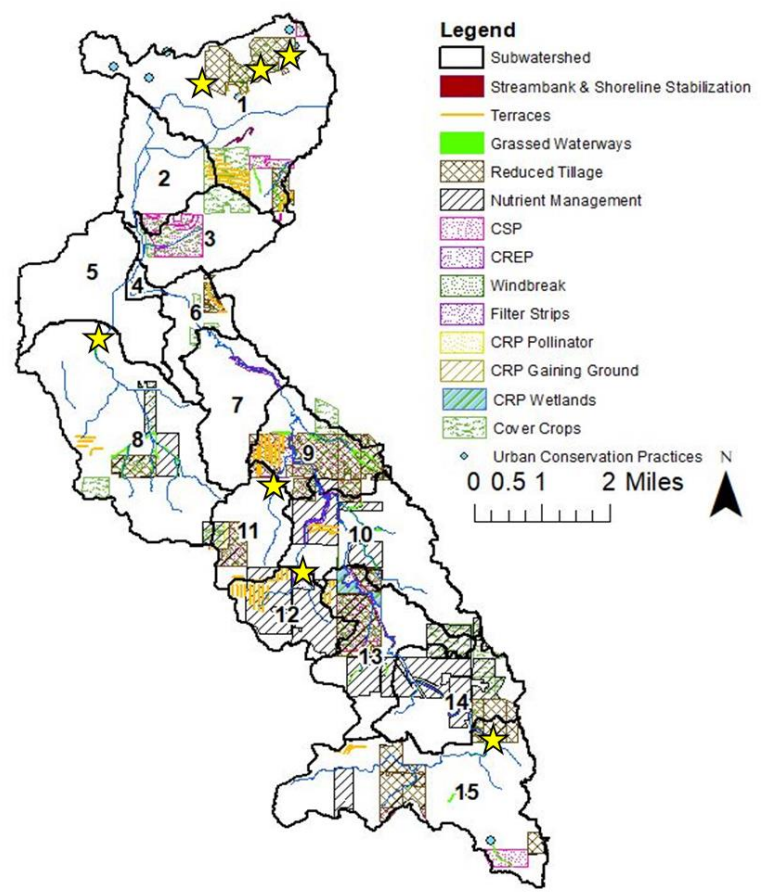


BHL monitoring includes three surface locations, two tile drain outlets, two potential no manure controls, and a public beach access location

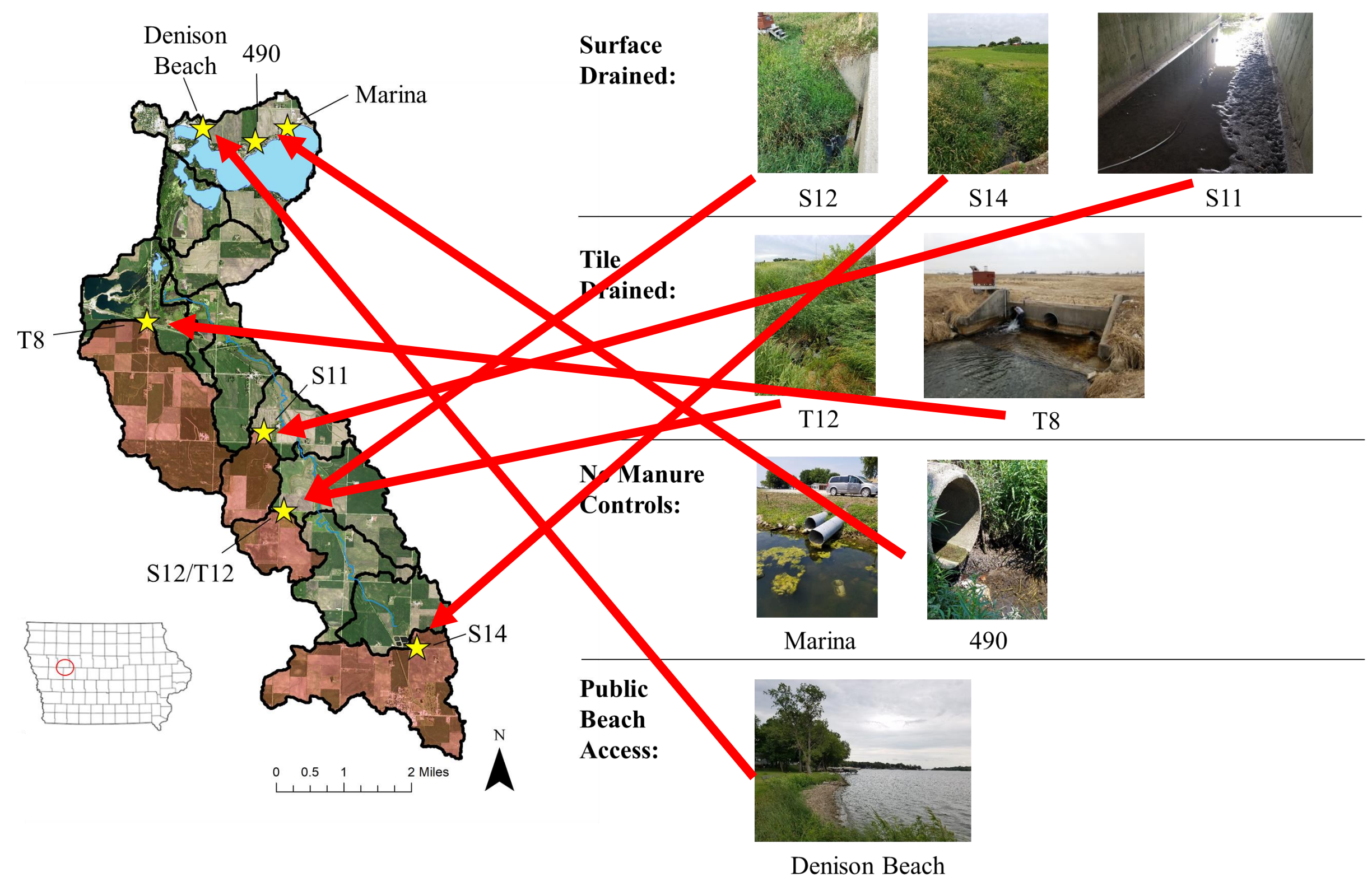




\section{Methods and Analysis}

- Grab samples every two weeks

- Samples preserved on ice during transportation

- Process samples within 24 hours

- Membrane filtration

- Plated on selective agar for:

- Total enterococci

- Tylosin resistant enterococci

- Tetracycline resistant enterococci

- Total E.coli

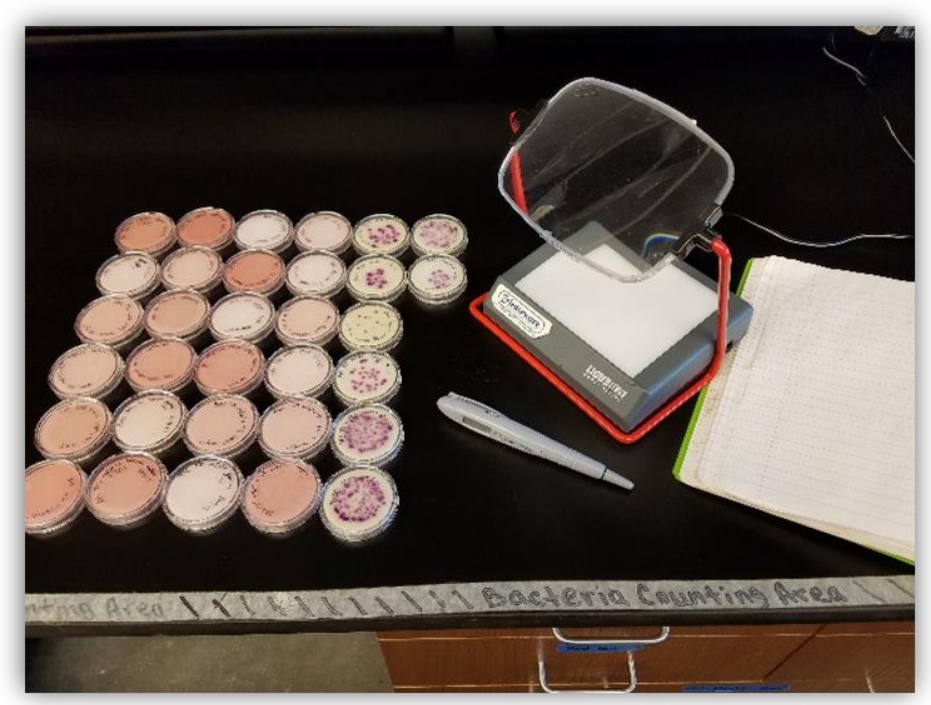


Single Sample Maximum (SSM) for waterbody class A2/A3-children's contact exceeded much of the time for enterococcus, less so for E.coli.
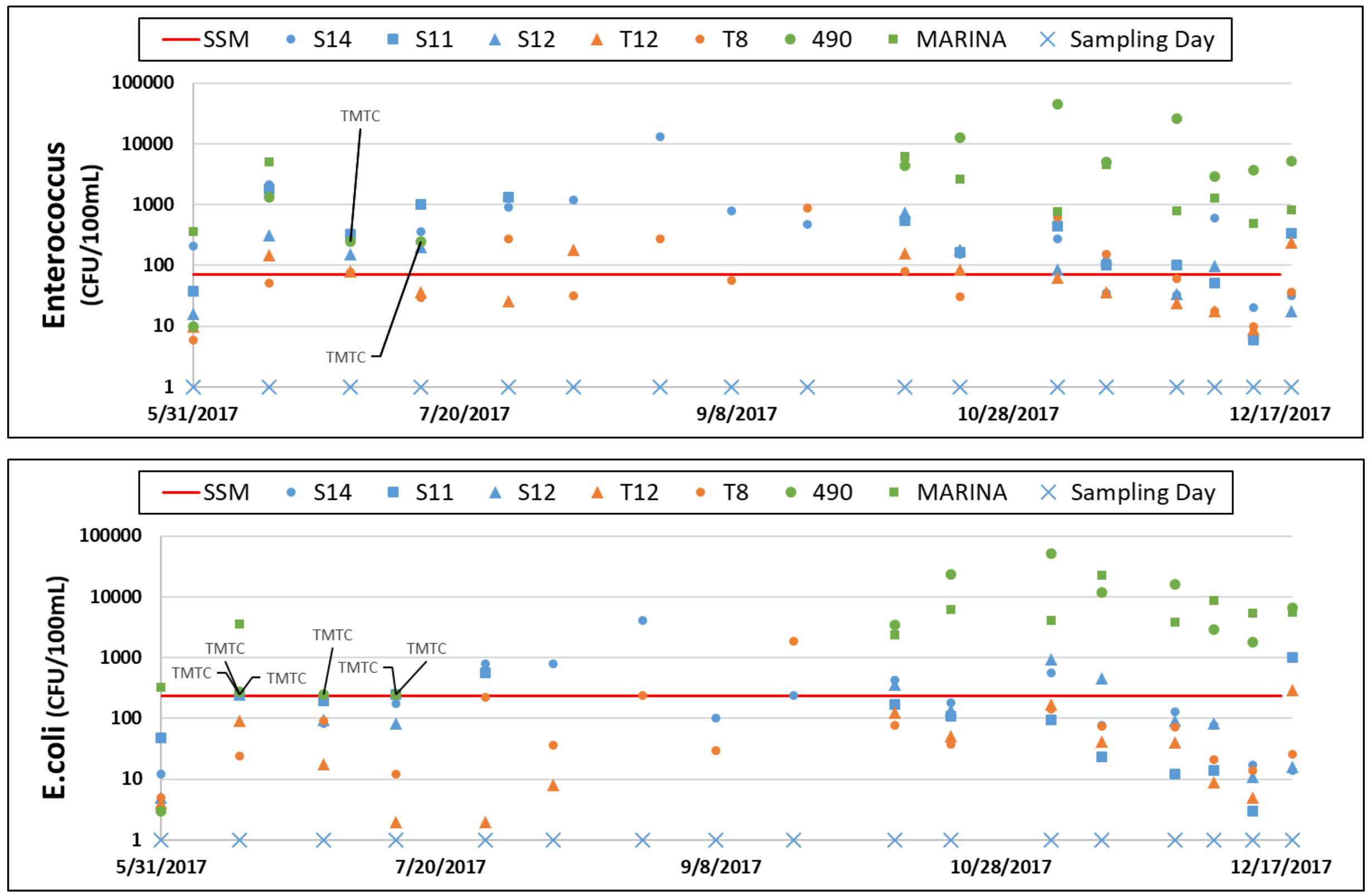
Tylosin and tetracycline antibiotic resistant enterococci were found in both surface and tile-drained water
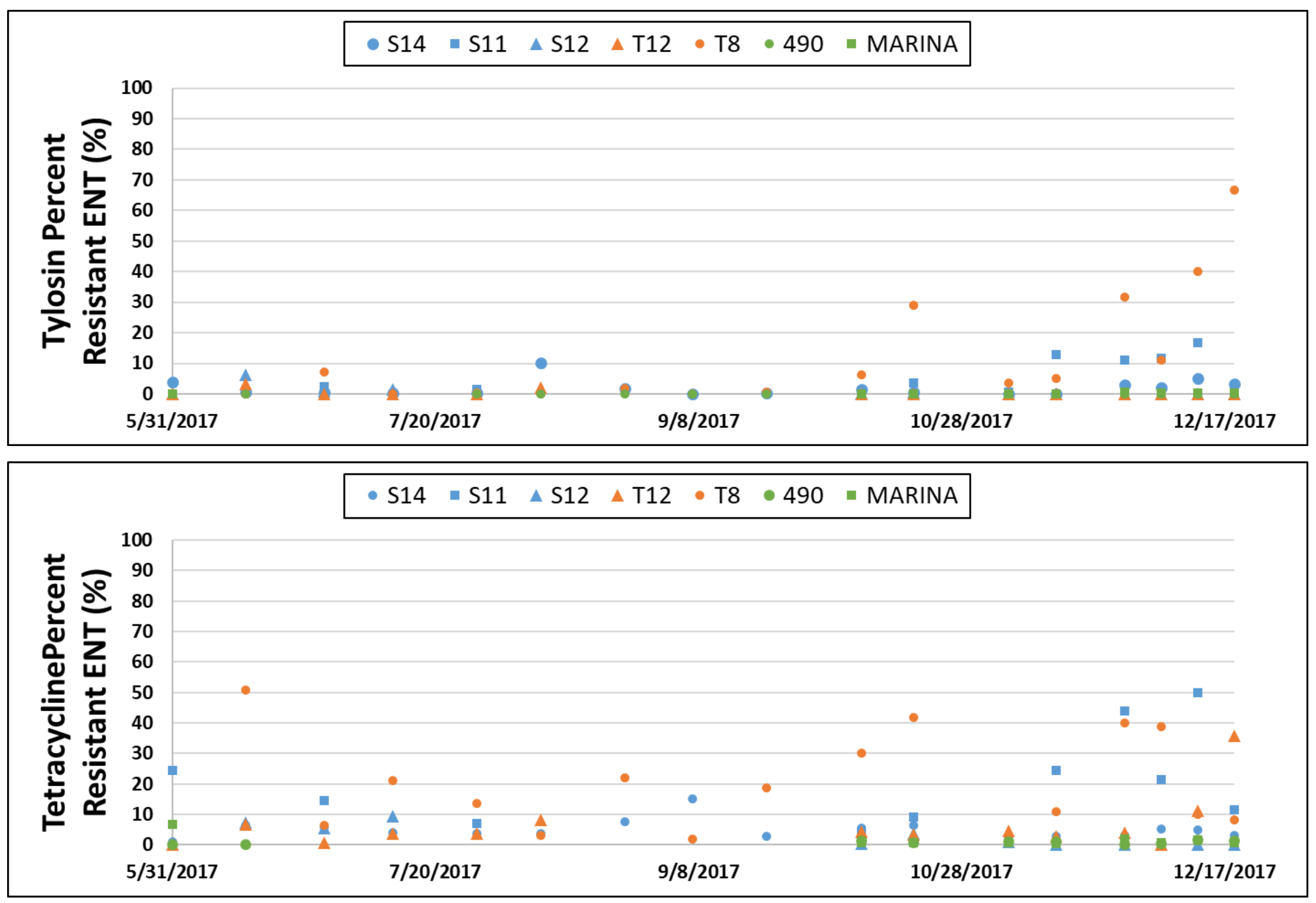


\section{Denison Beach}

Bacteria observed in the watershed do not reflect the bacteria observed in the lake

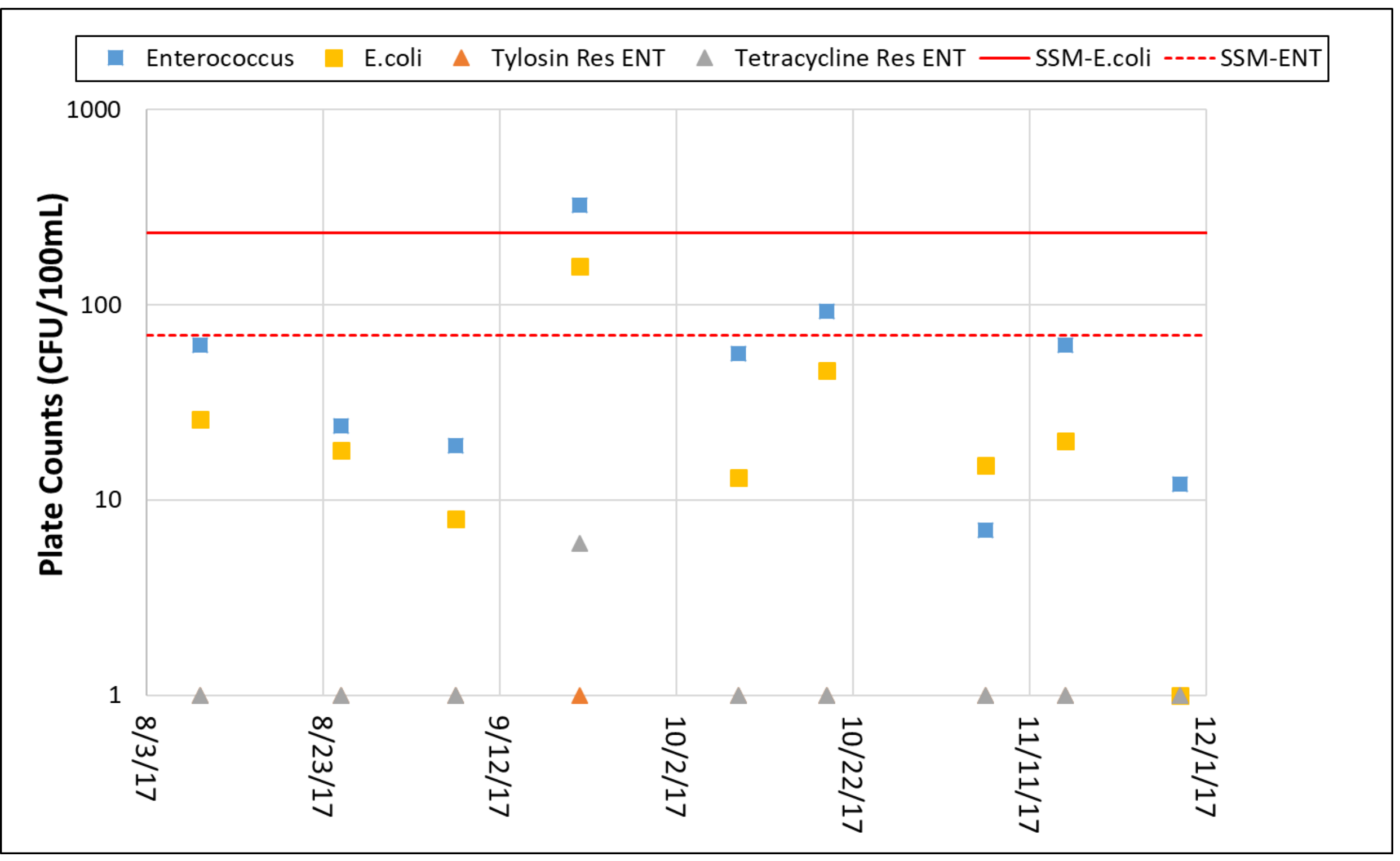


Higher percent resistance observed from watersheds with less BMP coverage

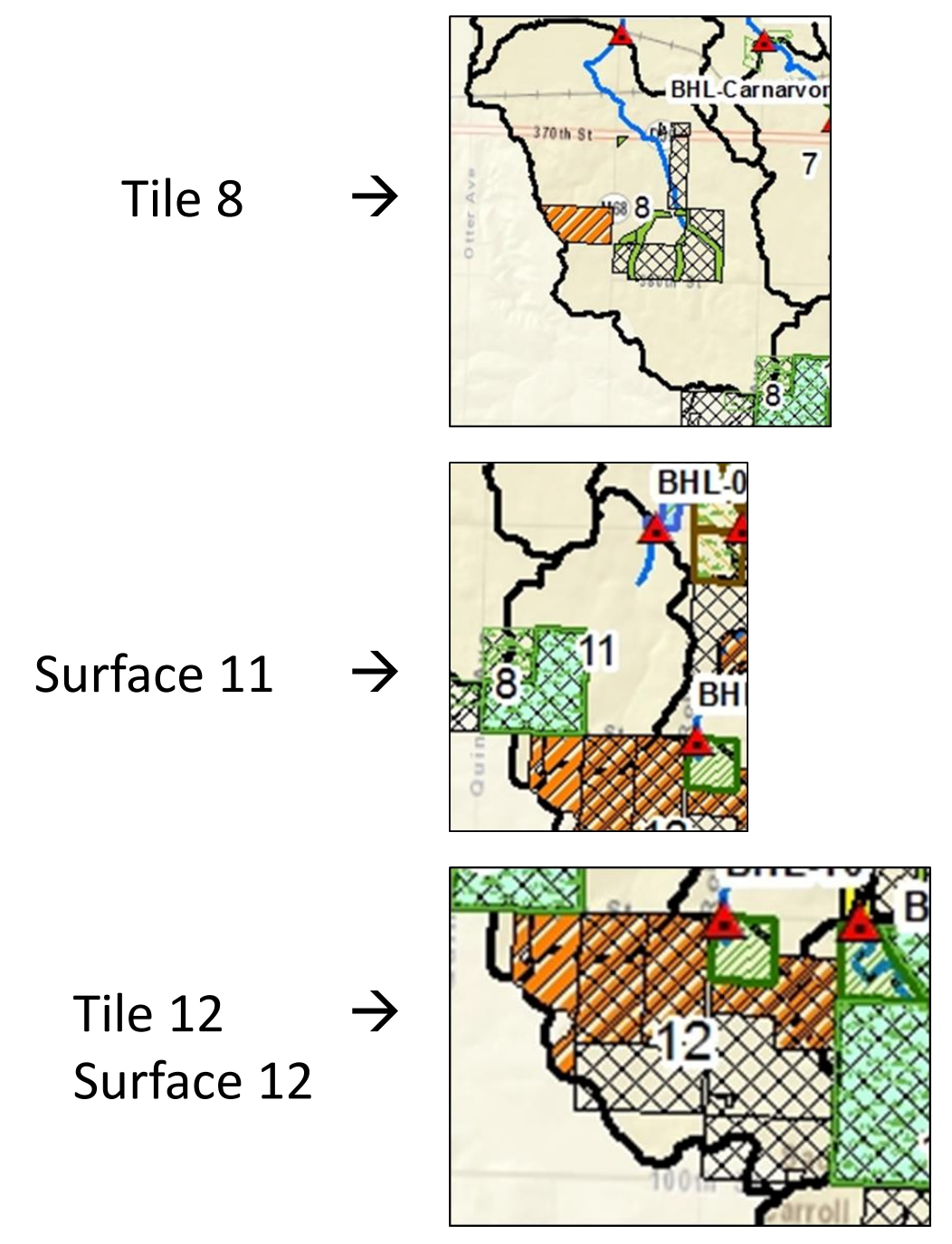

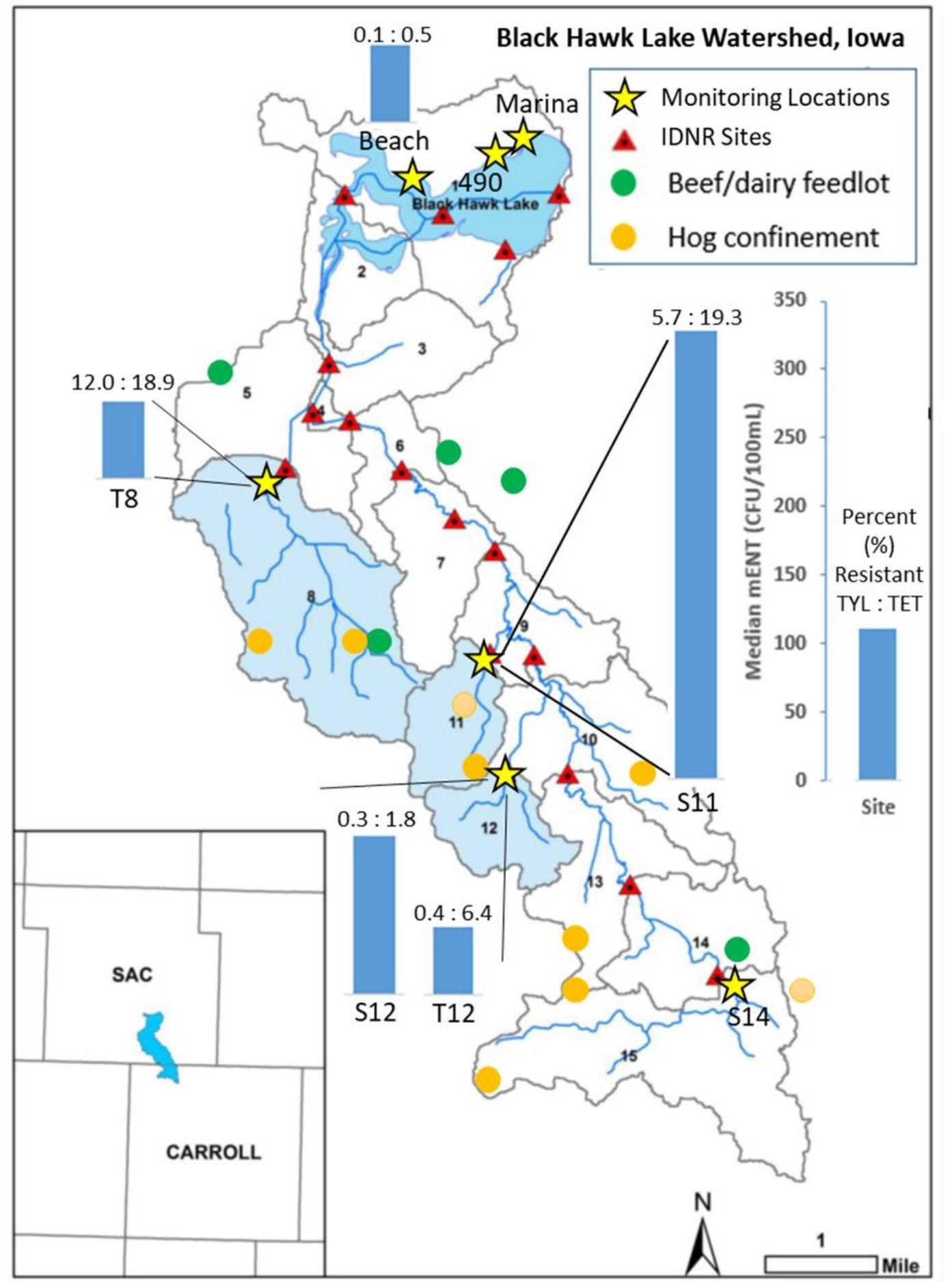




\section{Initial Conclusions}

- Observed lower percent resistance in subwatershed with higher best management practice coverage

- Observed antibiotic resistant fecal indicator bacteria in tile-drained water

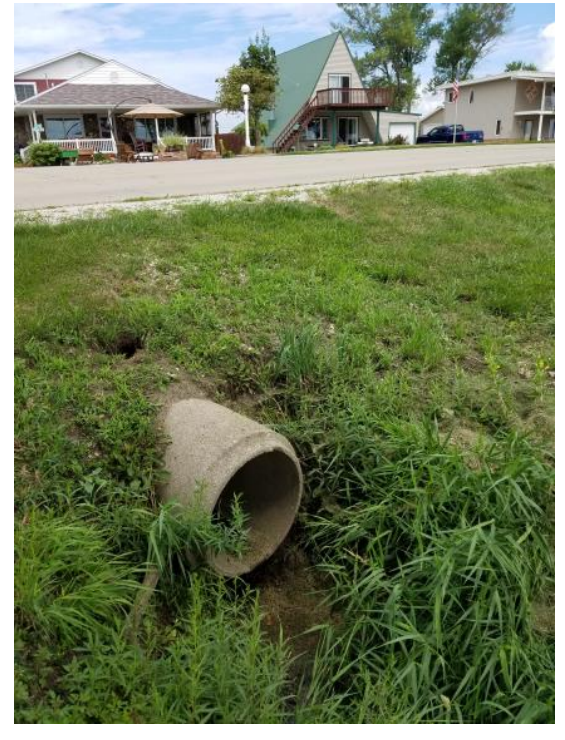

- Beach bacteria levels below the single sample maximum and antibiotic resistance is below the limit of detection
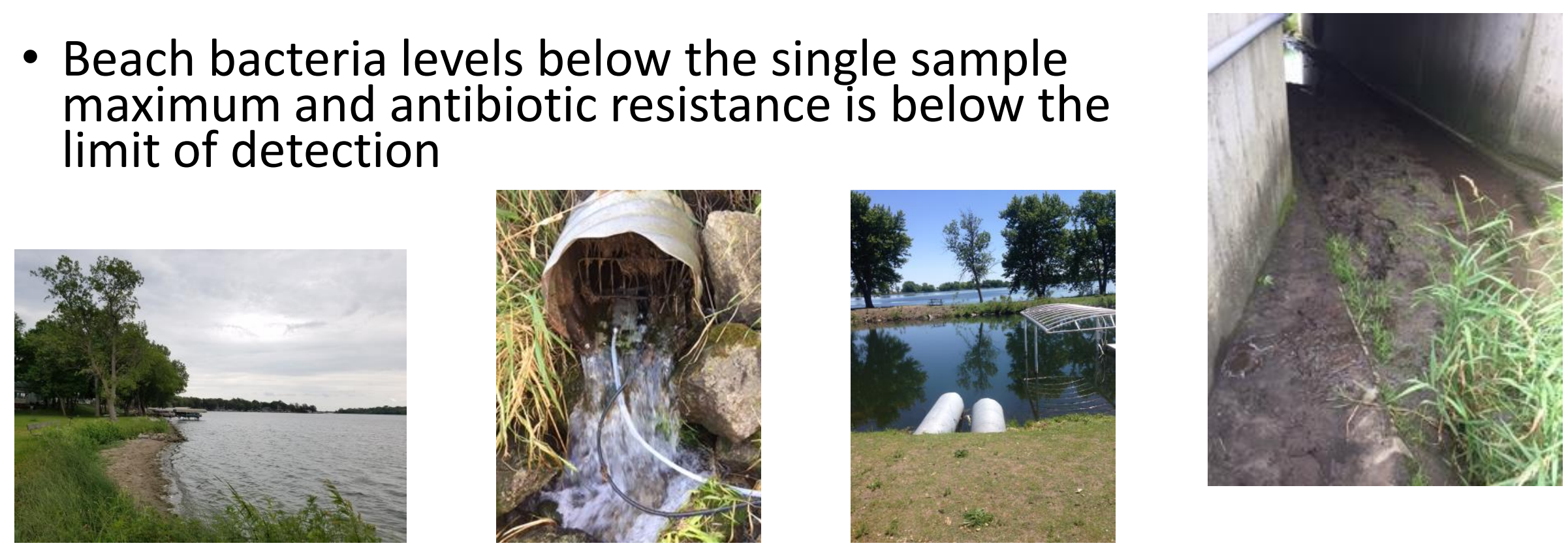


\section{Acknowledgements}

Funding: USDA

- Technical support: Leigh ann Long, Katherine van der Woude, Megan Lukas, Kyle Werning

- T.J. Lynn; watershed coordinator, Black Hawk Lake Watershed Project
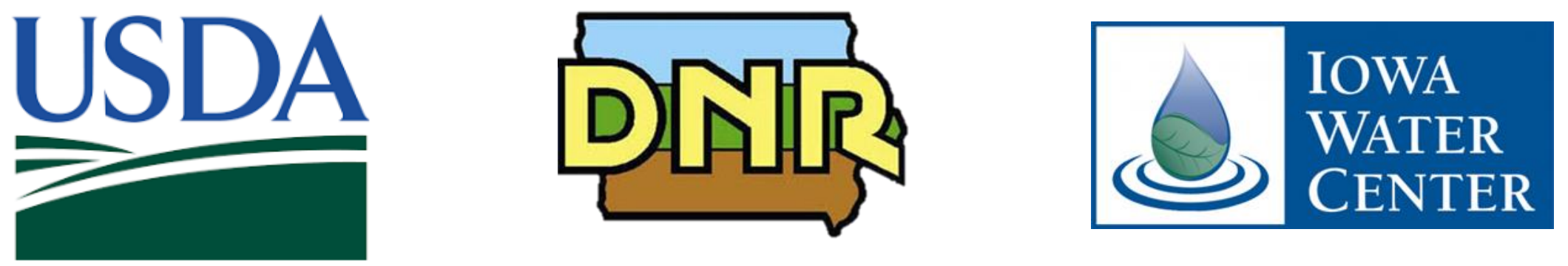


\section{Questions?}
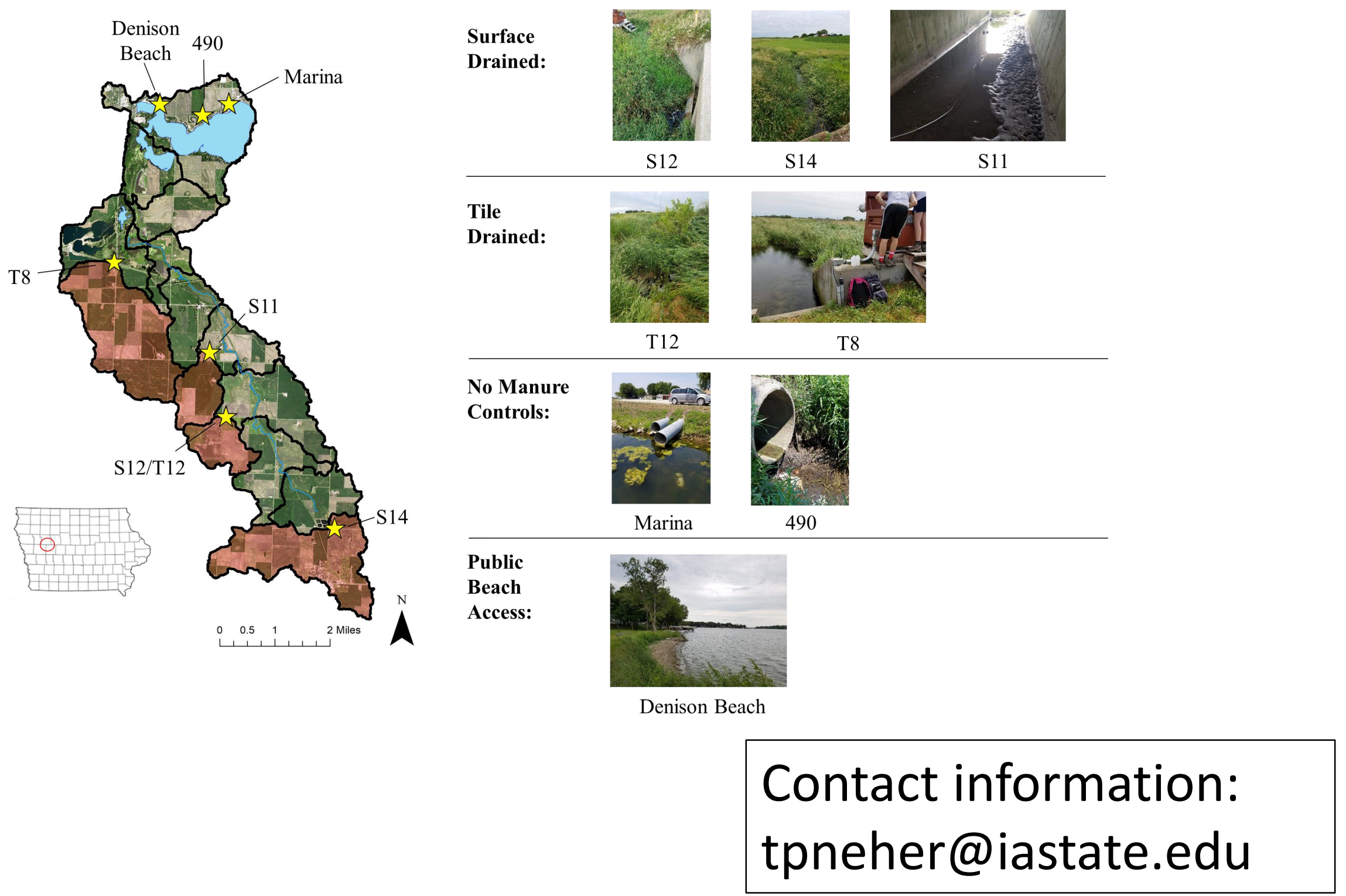